\title{
Experimental Observations and Numerical Modeling of a Single Coarse Lignite Particle Dried in Superheated Steam
}

\author{
Tsuyoshi Kiriyama*, Hideaki Sasaki, Akira Hashimoto, Shozo Kaneko and Masafumi Maeda \\ Institute of Industrial Science, The University of Tokyo, Tokyo 153-8505, Japan \\ The drying characteristics of a single coarse lignite particle in superheated steam are investigated. Spherical particles of Loy Yang lignite \\ $30 \mathrm{~mm}$ in diameter were used. The particles were dried with superheated steam at temperatures ranging from 110 to $170^{\circ} \mathrm{C}$ under atmospheric \\ pressure, and their weights and temperatures were measured with electronic balance, thermocouples and infrared thermograph. Condensation of \\ water droplets on the surface was observed initially, then constant drying rate period (CDRP) and decreasing drying rate period (DDRP) were \\ observed successively. A numerical model of the drying process was developed based on the results, taking into account transfer of free water \\ inside the particle, equilibrium moisture content and shrinkage of the lignite particle itself. [doi:10.2320/matertrans.M-M2013817]
}

(Received April 26, 2013; Accepted June 24, 2013; Published August 2, 2013)

Keywords: lignite, superheated steam drying, single-particle model, thermal power generation

\section{Introduction}

Lignite, often referred to as brown coal, is the lowest rank of coal and accounts for $23 \%$ of the proven recoverable reserves of all coal. ${ }^{1)}$ It contains more moisture and volatile matter than high-rank coals such as bituminous coal, and its calorific value is lower. The transportation costs of raw lignite are high due to its high moisture content. In addition, it is difficult to transport and store lignite after drying because it has a propensity to combust spontaneously. Therefore, lignite is mainly used as a fuel in thermal power stations located near source mines. Because water vaporization causes heat loss in lignite-fired power stations, a drying system is necessary to improve thermal efficiency and reduce $\mathrm{CO}_{2}$ emissions.

Drying lignite with superheated steam can prevent spontaneous combustion and using self-heat recuperation systems can improve thermal efficiency. Recently, a fluidized-bed dryer using superheated steam on a commercial scale has been developed by WTA (an abbreviation of Wirbelschicht-Trocknung mit interner Abwärmenutzung, which means fluidized-bed drying with internal waste heat utilization). ${ }^{2)}$ A pilot dryer using pressurized steam with a capacity of $10 \mathrm{t} / \mathrm{h}$ has been constructed at Schwarze Pumpe (Spremberg, Germany). ${ }^{3)}$

To determine optimal drying conditions, the behavior of lignite in superheated steam was investigated. A numerical model of a lignite particle was needed to address its size distribution in a dryer. Zhang and You reported experimental results and numerical model for drying single lignite particles with hot-air convection. ${ }^{4)}$ However, a single-particle model consistent with experimental results has not yet been proposed for superheated steam drying. A single-particle model proposed by Chen et al. was based on experiments with ceramic spheres and water droplets. ${ }^{5)}$ Although Looi et al. studied drying single lignite particles in superheated steam under pressure (1.7-8.4 bar) and developed a numerical model, that model predicted a lower drying rate than the experimental results. ${ }^{6}$
The purpose of this study is to observe the drying characteristics of lignite in superheated steam experimentally, and to develop a numerical model based on the results. A single Australian lignite particle with a diameter of $30 \mathrm{~mm}$ was dried in superheated steam, and changes in its weight, temperature and appearance were observed. A numerical model was then developed using the parameters obtained from the experiments.

\section{Experimental Method}

\subsection{Sample preparation}

Loy Yang lignite from Victoria, Australia, with a moisture content of about 62 mass\% was used. Blocks of raw lignite were cut into spherical samples $30 \mathrm{~mm} \pm 0.05 \mathrm{~mm}$ in diameter with a specialized tool, and their average weight was $16.0 \mathrm{~g}$. Figure 1 shows the sample and its setting scheme. A hole with a diameter of $0.5 \mathrm{~mm}$ was drilled in the sample, avoiding its center. A polyester thread was passed through the hole to suspend the sample under an electronic balance. Two pairs of K-type thermocouples were used to measure temperatures inside the lignite. One was for the center, and the other for the midpoint between the center and the surface. The thermocouples consisted of insulated alumel and chromel wires $0.1 \mathrm{~mm}$ in diameter, and were set in drilled

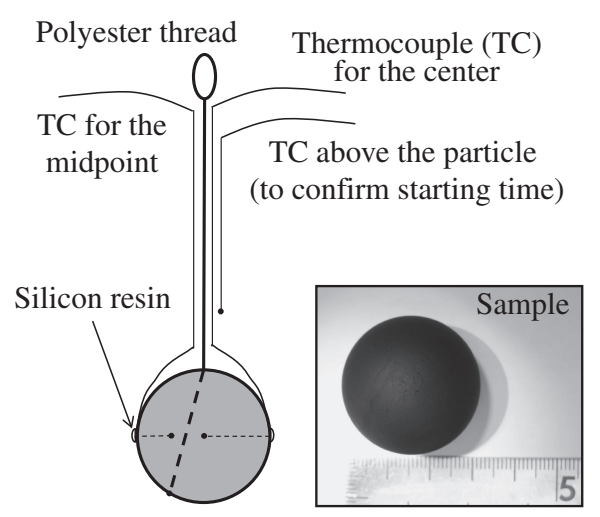

Fig. 1 Sample and its setting scheme. 


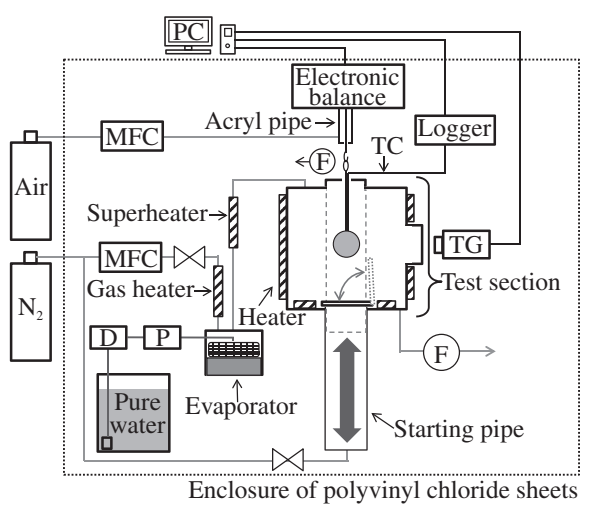

Fig. 2 Schematic configuration of experimental system. MFC: Mass flow controller, D: Degasser, P: Feed pump, TC: Thermocouple, TG: Thermograph, F: Exhaust fan.

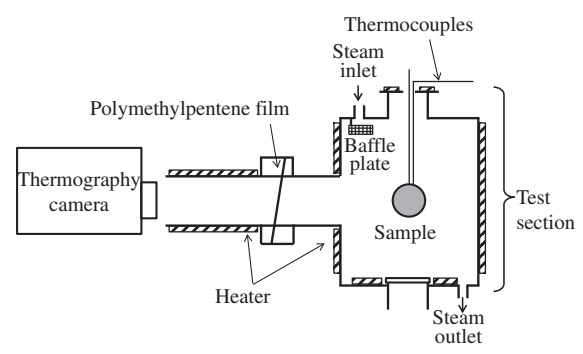

Fig. 3 Schematic illustration of steam flow in test section and optical path of thermography.

holes $0.3 \mathrm{~mm}$ in diameter. A minuscule quantity of silicon resin was used to fix them in position.

\subsection{Experimental apparatus}

Figure 2 is the schematic configuration of the experimental system. Sample weight, $W$, was measured with an electronic balance having a resolution of $0.1 \mathrm{mg}$ (HR-200, A \& D Company), and placed in a test section $133 \mathrm{~mm}$ in diameter and $152 \mathrm{~mm}$ in height. Temperature in the test section was controlled with surrounding heaters. Pure water was degassed and pumped up to an evaporator and a superheater. The superheated steam was sent into the top of the test section, to which a baffle plate was attached as shown in Fig. 3, and exhausted from the bottom using a fan. At the top of the test section, another small fan exhausted the leakage of superheated steam from an orifice, through which the hanging thread of the sample had been passed. Air was supplied into an acryl pipe attached under the balance along the suspension wire at a rate of $1.0 \mathrm{dm}^{3} / \mathrm{min}\left(\mathrm{ANR}, 20^{\circ} \mathrm{C}, 101325 \mathrm{~Pa}\right)$ to stabilize temperature and flow. The sample could be isolated from the atmosphere in the test section by raising the starting pipe.

Sample temperatures, $T$, were measured at its center and midpoint with K-type thermocouples as mentioned above. Surface temperature was measured with a thermograph (R$300, \mathrm{NEC} /$ Avio) having infrared bolometers in the range of wavelength detection from 8 to $12 \mu \mathrm{m}$. A window for the thermograph was located on the side of the test section, as shown in Fig. 3. The inside wall of this section and the optical path were painted with a black body spray having an emissivity of 0.94 (THI-1B, Tasco Japan). A polymethyl- pentene film $10 \mu \mathrm{m}$ thick (from The Japanese Consumers' Cooperative Union) was set in the optical path at an inclination of $10^{\circ}$ to avoid infrared reflection. The film had a heatproof temperature of $180^{\circ} \mathrm{C}$, and its average transmittance was $90 \%$ in the range of wavelengths from 8 to $12 \mu \mathrm{m}$. As shown in the results, lignite was maintained at $100^{\circ} \mathrm{C}$ for a period in the drying process and reached the temperature of superheated steam in the final state. Consequently, the thermograph was calibrated on the basis of these two temperatures assuming constancy of sample emissivity and surrounding temperature.

The sample was observed with a video camera (HDRCX170, Sony) through a glass window, which was located at the side of the test section making a right angle with the optical path for the thermograph.

The area indicated by the dotted line in Fig. 2 was enclosed with polyvinyl chloride sheets to prevent any fluctuations caused by air. The relative humidity in the enclosure was maintained at over $45 \%$ to eliminate the effects of static electricity.

\subsection{Experimental procedure}

Considering the spontaneous combustion temperatures of Loy Yang lignite $\left.\left(160-170^{\circ} \mathrm{C}\right)\right)^{7)}$ the samples were dried at 110, 130,150 and $170^{\circ} \mathrm{C}$ (hereafter referred to as: test temperature). Before setting the sample, a test section was heated to the test temperature under a flow of nitrogen, then the fluid was replaced with superheated steam. The test section was presumed to be filled with superheated steam under atmospheric pressure from this point. The feed rate of water into the evaporator was $8 \mathrm{~cm}^{3} / \mathrm{min}$. Calculated from cross-sectional area, the average velocity of superheated steam was about $0.02 \mathrm{~m} \mathrm{~s}^{-1}$ in the test section. The Reynolds number was about 20 in this condition, which enabled accurate weighing of the sample in a laminar flow. After the test section was stabilized, the starting pipe was lifted to separate its internal space from the test section. The inside of the starting pipe was then purged with nitrogen, and the sample was set in position. From the time the starting pipe was lowered again, the sample was exposed to superheated steam and measurements were started. The start of drying was also monitored with a thermocouple placed above the sample (Fig. 1). $W$ and $T$ were recorded every $1 \mathrm{~s}$, with the exception of the test at $110^{\circ} \mathrm{C}$, during which they were recorded every $5 \mathrm{~s}$ after the first $1 \mathrm{~h}$. Drying was judged to have been completed when the change in $W$ per minute became less than $0.5 \mathrm{mg}$, which was less than $0.01 \%$ of dried sample weight. Subsequently, the fluid was switched to nitrogen, and the sample was dried for over $3 \mathrm{~h}$ to evaporate any residual water. Sample weight after nitrogen drying was regarded as the weight of coal contained in the lignite (dry coal), $W_{\mathrm{c}}$. The weight of water in the lignite, $W_{\mathrm{w}}$, was determined by subtracting $W_{\mathrm{c}}$ from the weight of the sample, $W$. The experiments were conducted three times at each test temperature.

\subsection{Evaluation of shrinkage}

After final drying in nitrogen, the volume of the spherical sample, $V$, was measured with a 3D scanner (VIVID9i, Konica Minolta) to evaluate shrinkage. Three rod-shaped 

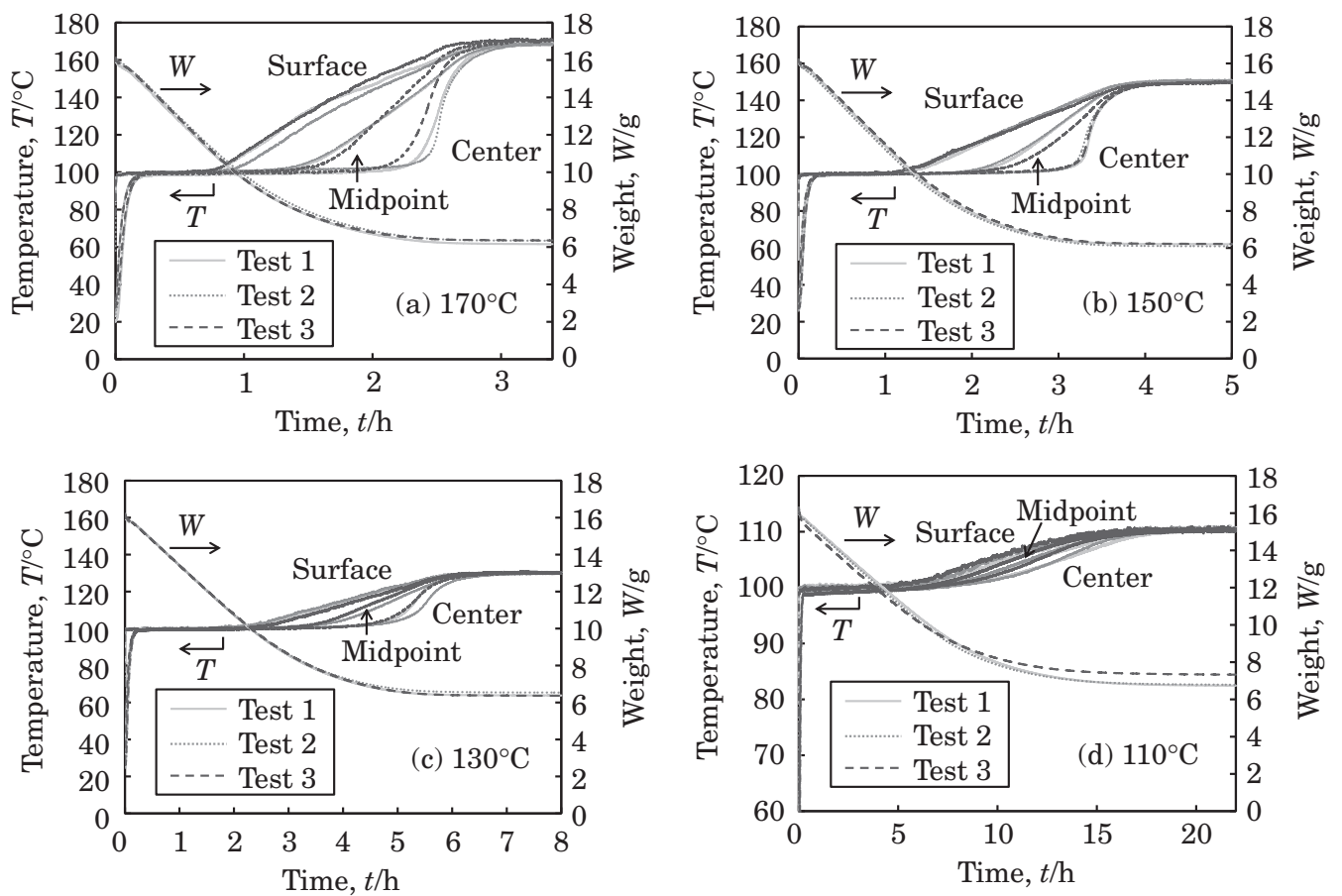

Fig. 4 Temperatures and weights at test temperatures of (a) 170 , (b) 150 , (c) 130 and (d) $110^{\circ} \mathrm{C}$.

lignite samples were also prepared for complementary experiments. Their initial lengths, $l_{\text {ini }}$ and average diameters were $36-50$ and $2.7-5.5 \mathrm{~mm}$, respectively. The samples were dried in another electronic balance under a flow of nitrogen at room temperature, and their lengths, $l$, were measured with a micrometer during the drying process. After all weight changes had actually stopped, the samples were dried for $3 \mathrm{~h}$ in nitrogen at $105^{\circ} \mathrm{C}$, and their final weights and lengths were measured.

\section{Experimental Results and Discussion}

\subsection{Changes in temperature and weight during drying}

Temperatures and weights of samples when dried with superheated steam are shown in Fig. 4. Figure 5 shows video images at each moisture content, which is defined as the weight of water divided by that of dry coal, $X=W_{\mathrm{w}} / W_{\mathrm{c}}$. Initial moisture content was around 1.63 for all samples, as shown later in Figs. 7 and 14.

Initially, drop-wise condensation of steam occurred on the surface (Fig. 5), and temperatures rose (Fig. 4). Figure 6 is a magnified view of changes during this initial period at the test temperature of $170^{\circ} \mathrm{C}$. Just after starting the tests, sample weight increased by about $0.16 \mathrm{~g}$ due to the condensation of superheated steam and then showed a sharp decrease. Increase and decrease of the weight were repeated around a dozen times, representing condensation and falling water droplets. The falling droplets were also observed in video images. The fluctuations of the weight were observed even below its initial value $(15.86,16.03$ and $15.93 \mathrm{~g}$ for test 1,2 and 3 , respectively), suggesting that the water droplets were not only the result of the condensation of superheated steam. Therefore, water originally present in the lignite is believed to swell due to the rise in temperature, and to exude from the particle.
As time passed, sample temperatures at the surface, midpoint and center reached $100^{\circ} \mathrm{C}$ in that order, and were then maintained for a period. Sample weight decreased constantly during this period, and cracks were generated on the surface. Then, the temperatures at the surface, midpoint and center began rising again from $100^{\circ} \mathrm{C}$ in that order, and reached the test temperature. Surface drying during this period appeared on video images as the formation and widening of cracks (Fig. 5), with more cracks observed at higher test temperatures. The drying process was completed at 3, 4.5, 7.5 and $21 \mathrm{~h}$ with test temperatures of 170, 150, 130 and $110^{\circ} \mathrm{C}$ (Fig. 4), respectively. Cracks generated were closed in the final state due to shrinkage of the sample (Fig. 5).

Although temperature variations during drying showed the same tendency in all tests, there was a small difference between times at which temperature began rising from $100^{\circ} \mathrm{C}$. For instance, in tests at $170^{\circ} \mathrm{C}$, temperatures at surface and center rose earlier in test 3 than in test 2 by about 10 and $12 \mathrm{~min}$, respectively. The deviation might have been caused by the relative positions of thermocouple and cracks generated, the locations and shapes of which varied according to the sample.

\subsection{Moisture content and drying rate}

Figure 7 shows moisture contents, $X$, and drying rates, $-\mathrm{d} X / \mathrm{d} t$, at the test temperature of $170^{\circ} \mathrm{C}$. Results at other test temperatures are shown in Fig. 14 with simulation results. The drying rates were smoothed by calculating the moving average of $60 \mathrm{~s}$. Both constant drying rate period (CDRP) and decreasing drying rate period (DDRP) were observed in all tests. During CDRP, the temperature of the overall sample was $100^{\circ} \mathrm{C}$. This is reasonable because heat transfer into the surface was constant during this period, and heat was consumed only by the evaporation of water. Considering 

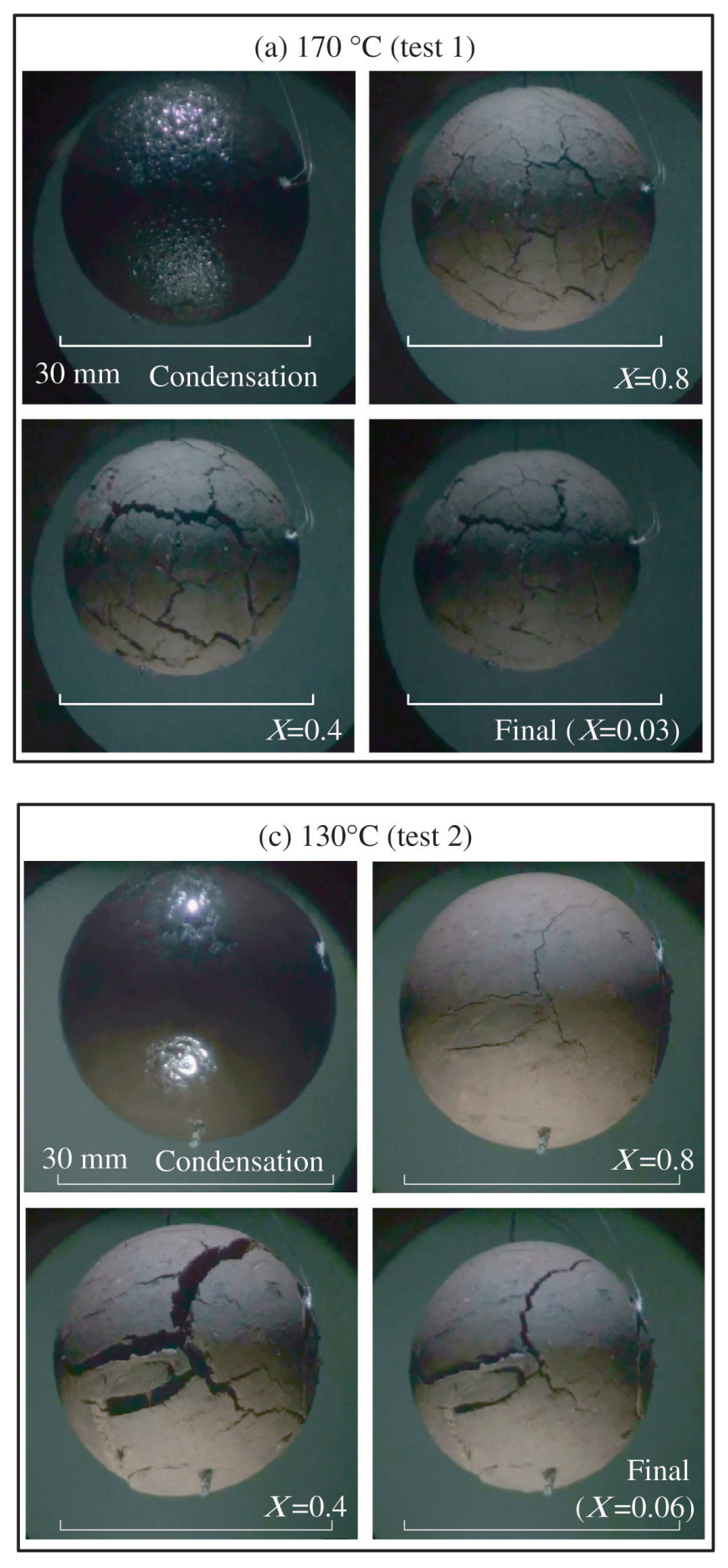

Fig. 5 Video images at test temperatures of (a) 170 , (b) 150 , (c) 130 and (d) $110^{\circ} \mathrm{C}$.

that surface temperature remained at $100^{\circ} \mathrm{C}$, "free water" is believed to transfer from the inner part to the surface. (The schematic illustration of the drying process is shown later in Fig. 10.) When the free water was depleted on the surface, temperature rose from $100^{\circ} \mathrm{C}$ and drying rate decreased until drying had actually finished. The experimental results shown above demonstrate the typical drying characteristics of superheated steam. ${ }^{8)}$

\subsection{Initial and residual water content in a sample and evaluation of shrinkage}

Figure 8 shows water percentages by weight, $W_{\mathrm{w}} /\left(W_{\mathrm{c}}+\right.$
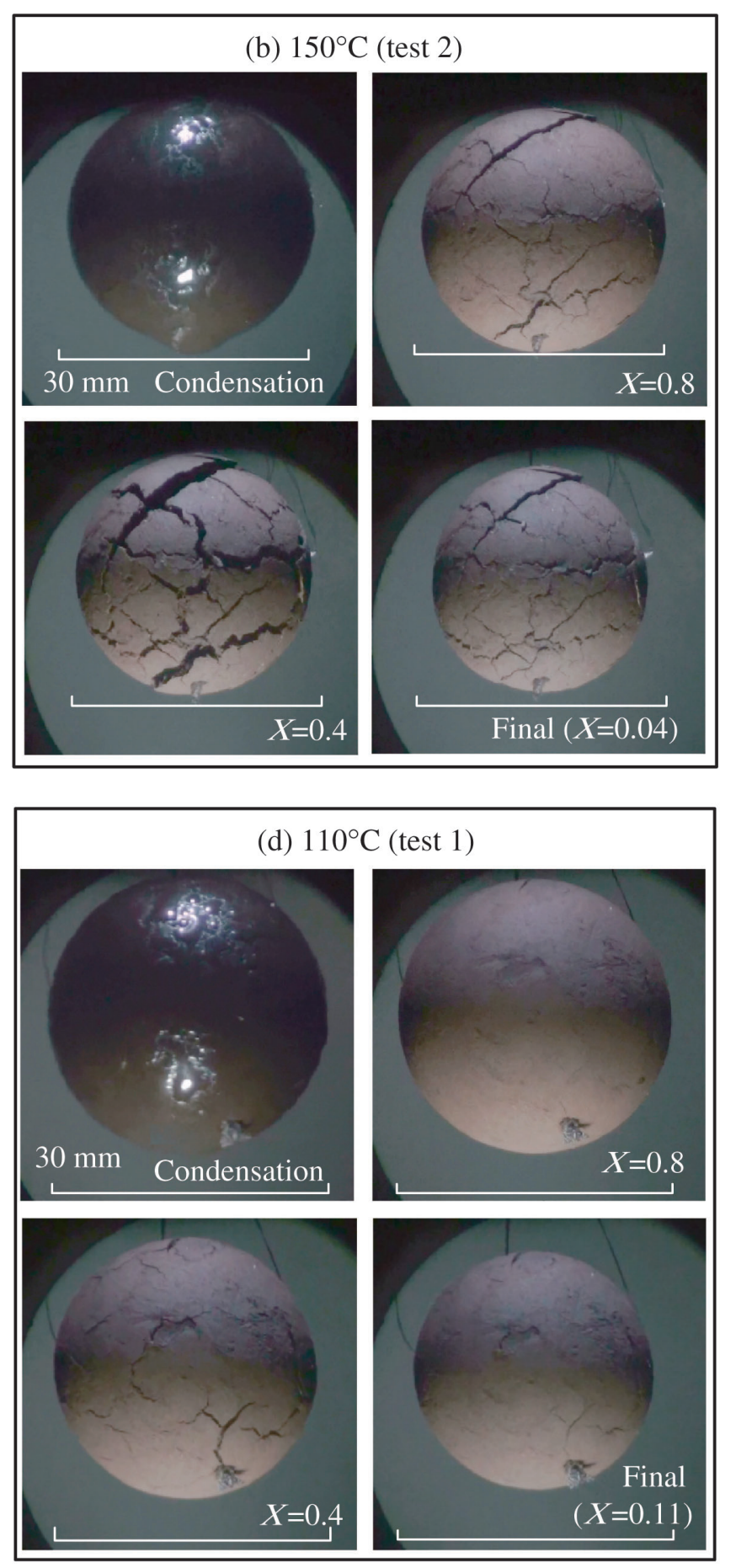

$\left.W_{\mathrm{w}}\right) \times 100$, in spherical samples before and after drying with superheated steam. Average value of water percentages was 62 mass\% (moisture content: 1.63) initially, but did vary slightly and probably caused deviations in the experimental results. For example, in the measurement at $110^{\circ} \mathrm{C}$, the moisture content of the sample in test 3 was lower than in tests 1 and 2 , and might have affected the deviation in Figs. 4(d) and 14(d).

Average values of residual water percentages were 10.9, 5.4, 3.6 and 2.9 mass $\%$ at $110,130,150$ and $170^{\circ} \mathrm{C}$, respectively. The residual water is considered to be bound water, which is strongly adsorbed in lignite. 


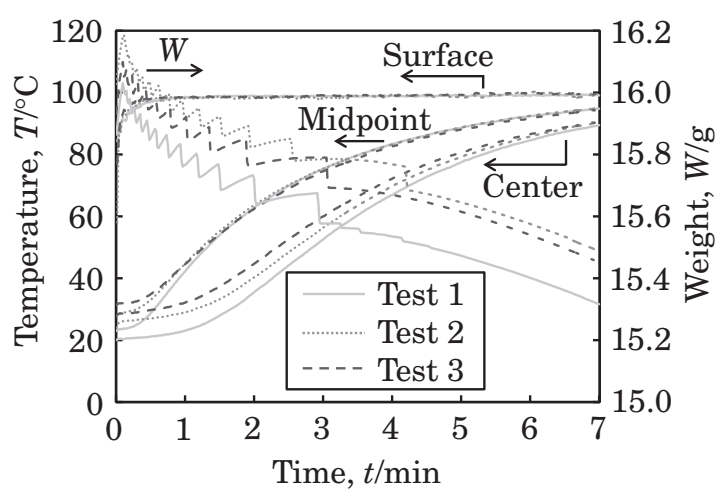

Fig. 6 Temperatures and weights during the initial period $\left(170^{\circ} \mathrm{C}\right)$.

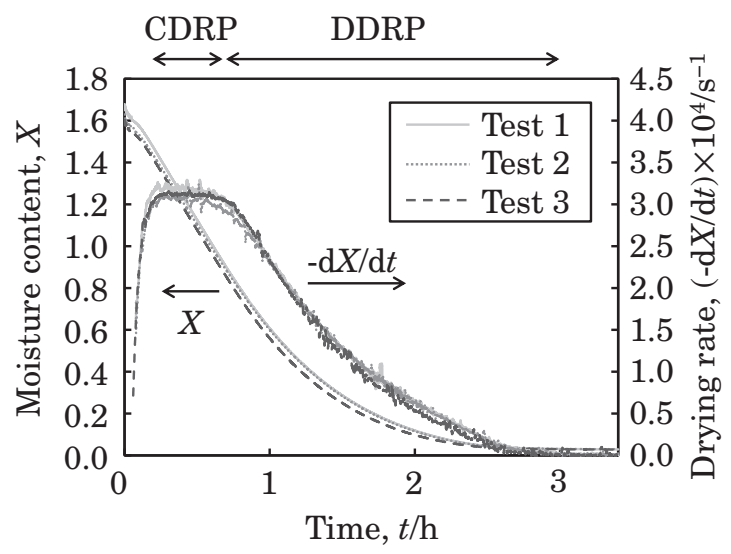

Fig. 7 Moisture contents and drying rates at the test temperature of $170^{\circ} \mathrm{C}$.

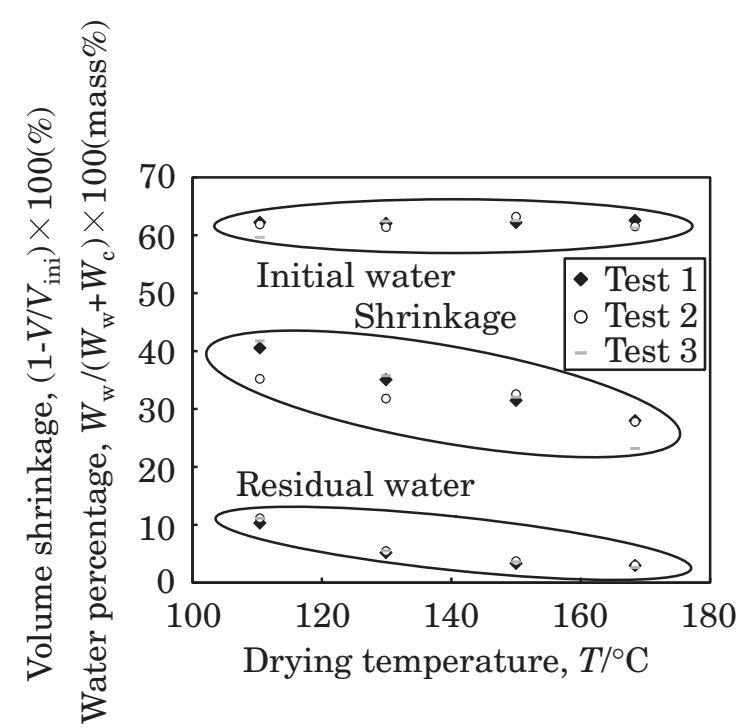

Fig. 8 Initial and residual water percentages and volume shrinkages.

Volume shrinkages of spherical samples after nitrogen drying, $\left(1-V / V_{\text {ini }}\right) \times 100$, are also shown in Fig. 8 . Shrinkage was smaller at higher test temperatures, probably due to cracks formed during the drying process. More cracks were generated at higher test temperatures (Fig. 5) and they prevented homogeneous shrinkage, resulting in more vacant space in the dried lignite.

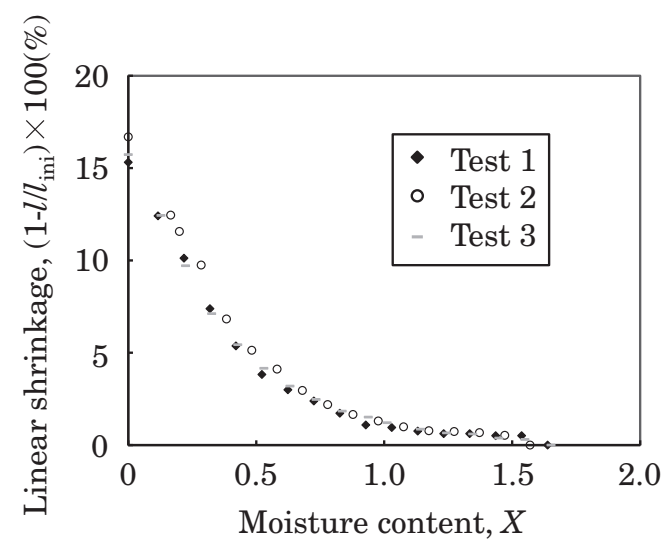

Fig. 9 Linear shrinkages measured with rod-shaped samples.

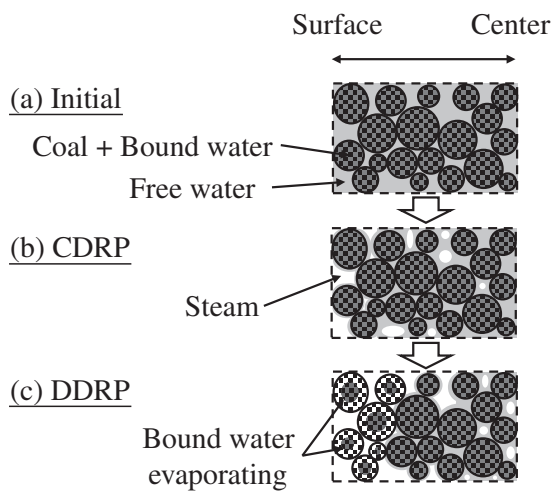

Fig. 10 Schematic illustration of drying process. (a) Initial state, (b) Constant drying rate period and (c) Decreasing drying rate period.

The shrinkages of rod-shaped samples, which were dried at lower temperatures, are shown in Fig. 9. The average of linear shrinkages, $\left(1-l / l_{\text {ini }}\right) \times 100$, was $16 \%$ after nitrogen drying at $105^{\circ} \mathrm{C}$. This is equivalent to a volume shrinkage of $41 \%$, which agrees with the shrinkage of the spherical sample dried at $110^{\circ} \mathrm{C}(40 \%$ in Fig. 8). The decrease in volume corresponds to $59 \%$ of the volume of evaporated water. A similar result was reported for Yallourn lignite in Victoria (about 60\%). ${ }^{9}$ )

\section{Numerical Modeling}

\subsection{Physical model}

A numerical model for drying lignite has been developed based on the physical model illustrated in Fig. 10.

Lignite was assumed to consist of dry coal, free water and bound water (Fig. 10(a)). The free water is defined as water that evaporates at $100^{\circ} \mathrm{C}$ under atmospheric pressure, and bound water is defined as water that evaporates above $100^{\circ} \mathrm{C}$. Initial moisture content is $1.63(62 \mathrm{mass} \%)$ from the experimental results. The water accounting for moisture contents from 1.63 to 0.56 is regarded as free water, and the remainder as bound water. This classification is based on reports by others, ${ }^{10,11)}$ who found a part of the water in lignite did not freeze (i.e., transform from liquid phase to solid phase) at $0^{\circ} \mathrm{C}$, suggesting the presence of bound water. They reported a moisture content of 0.56 as the border between 


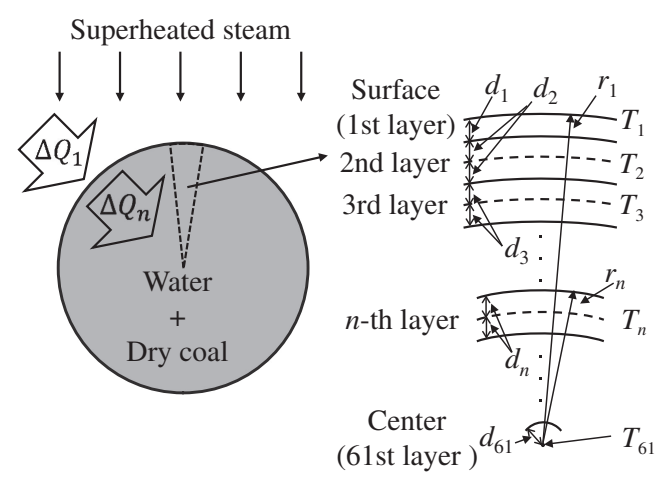

Fig. 11 Simulation model.

bound water and free water in Loy Yang lignite. Volume fractions of coal, water and steam $\left(\varphi_{\mathrm{c}}, \varphi_{\mathrm{w}}\right.$ and $\varphi_{\mathrm{s}}$, respectively) were taken into account. Calculated from the density of samples $\left(1.13 \times 10^{3} \mathrm{~kg} / \mathrm{m}^{3}\right)$ and the initial water percentage $(62 \mathrm{mass} \%)$, the weight of water is $7.0 \times 10^{2}$ $\mathrm{kg} / \mathrm{m}^{3}$ in raw coal. Assuming that the density of water in lignite is $1.0 \times 10^{3} \mathrm{~kg} / \mathrm{m}^{3}, \varphi_{\mathrm{w}}$ and $\varphi_{\mathrm{c}}$ in the initial state were estimated to be 0.7 and 0.3 , respectively. Free water evaporates at $100^{\circ} \mathrm{C}$ during the drying process, and its space becomes occupied by steam as shown in Fig. 10(b); meanwhile, free water is supplied from the inside to the surface, resulting in CDRP. After free water on the surface has evaporated completely, the temperature rises from $100^{\circ} \mathrm{C}$, and DDRP starts with the evaporation of bound water (Fig. 10(c)).

Figure 11 shows a simulation model. If a lignite particle is assumed to be isotropic, a one-dimensional model can be used. A particle $30 \mathrm{~mm}$ in diameter is divided into 61 concentric spherical shells with an initial thickness of $0.25 \mathrm{~mm}$, except for surface and center layers, which are $0.125 \mathrm{~mm}$ thick. The 61 layers are numbered from surface (1st) to center $(61 \mathrm{st})$, and outer radius of the $n$-th layer is represented by $r_{n}$.

Weight and temperature in each layer are assumed to be homogeneous, and the temperature of $n$-th layer, $T_{n}$, is represented by the midpoint in the radial direction for $2 \leq n \leq 60$. For the 1 st and 61 st layers, temperatures are represented by the surface and center of the particle, respectively. Distance from the representative point of $n$-th layer to the next layer is defined as $d_{n}$.

Transfer and consumption of heat, evaporation and transfer of water, and shrinkage during the drying process on these layers are considered in the following numbered segments.

Parameters used in this simulation are listed in Table 1.

\subsection{Heat transfer to the surface}

Initial temperature of lignite is $30^{\circ} \mathrm{C}$. When the temperature of the $1 \mathrm{st}$ layer, $T_{1}$, is below $100^{\circ} \mathrm{C}$, heat flux to the surface, $\Delta Q_{1}$, is mainly considered to be accomplished by the condensation of steam. Assuming the condensed water on the surface is $100^{\circ} \mathrm{C}$, heat transfer $\Delta Q_{1}$ is expressed by eq. (1).

$$
\begin{array}{r}
\Delta Q_{1}=\Delta Q_{\text {cond }}=h_{\text {cond }} \cdot 4 \pi r_{1}^{2}\left(100-T_{1}\right) \cdot \Delta t, \\
\text { for } T_{1}<100
\end{array}
$$

where $h_{\text {cond }}$ is the condensing heat transfer coefficient and $r_{1}$ equals the radius of the particle. Time step, $\Delta t$, is $0.001 \mathrm{~s}$ in this calculation.

After the surface reaches $100^{\circ} \mathrm{C}$, the temperature is assumed to be maintained until the condensed and exuded free water on the surface dry up. Therefore, $\Delta Q_{1}$ equals heat flux to the inner layer, $\Delta Q_{2}$, which is defined in 4.3.

$$
\Delta Q_{1}=\Delta Q_{2}, \quad \text { for } T_{1}=100 \text { and } M_{\text {surf }}>0
$$

where $M_{\text {surf }}$ is the weight of condensed and exuded water on the surface layer introduced in 4.5.

After water on the surface layer evaporates, heat transfer to the surface layer is assumed to be accomplished by convection and radiation as expressed by eq. (3).

$$
\begin{aligned}
& \Delta Q_{1}=\Delta Q_{\mathrm{conv}}+\Delta Q_{\mathrm{rad}}, \\
& \text { for } T_{1} \geq 100 \text { and } M_{\text {surf }}=0 \\
& \Delta Q_{\text {conv }}=h_{\text {conv }} \cdot 4 \pi r_{1}^{2}\left(T_{\mathrm{a}}-T_{1}\right) \cdot \Delta t \\
& \Delta Q_{\mathrm{rad}}=e_{\mathrm{r}} \cdot \sigma \cdot 4 \pi r_{1}^{2}\left(\left(T_{\mathrm{a}}+273.15\right)^{4}\right. \\
& \left.-\left(T_{1}+273.15\right)^{4}\right) \cdot \Delta t
\end{aligned}
$$

where $h_{\text {conv }}$ is convective heat transfer coefficient, $T_{\mathrm{a}}$ is temperature of superheated steam (test temperature), $e_{\mathrm{r}}$ is relative emissivity assumed to be constant at 0.94 for the inside of the test section and the surface of a lignite particle and $\sigma$ is Stefan-Boltzmann constant. If the Reynolds number is small in the test section, $h_{\text {conv }}$ is expressed by eq. (6) assuming laminar flow and natural convection. ${ }^{12)}$

$$
\begin{gathered}
h_{\text {conv }}=N u \frac{k_{\mathrm{a}}}{2 r_{1}} \\
N u=2+0.760 C_{T}(P r) R a^{m}
\end{gathered}
$$

where $N u$ is Nusselt number, $k_{\mathrm{a}}$ is thermal conductivity of superheated steam, $C_{T}$ is function of the Prandtl number, $R a$ is Rayleigh number and $m$ is function of the Rayleigh number (Table 1).

\subsection{Heat transfer inside the lignite particle}

Heat input to the $n$-th layer from the outer layer by conduction, $\Delta Q_{n}$, is expressed by eq. (8).

$$
\begin{array}{r}
\Delta Q_{n}=k_{n-1, n} /\left(d_{n-1}+d_{n}\right) \cdot 4 \pi r_{n}^{2}\left(T_{n-1}-T_{n}\right) \cdot \Delta t, \\
\text { for } 2 \leq n \leq 61
\end{array}
$$

where $k_{n-1, n}$ is thermal conductivity between adjacent layers. $k_{n-1, n}$ is expressed by eq. (9).

$$
\begin{gathered}
k_{n-1, n}=\left(d_{n-1}+d_{n}\right) /\left(\frac{d_{n-1}}{k_{n-1}}+\frac{d_{n}}{k_{n}}\right), \\
\text { for } 2 \leq n \leq 61 \\
k_{n}=\varphi_{\mathrm{w}} k_{\mathrm{w}}+\varphi_{\mathrm{c}} k_{\mathrm{c}}+\varphi_{\mathrm{s}} k_{\mathrm{s}} \\
\varphi_{\mathrm{w}}+\varphi_{\mathrm{c}}+\varphi_{\mathrm{s}}=1
\end{gathered}
$$

where $k_{n}$ is thermal conductivity of the layer calculated using eq. (10) from thermal conductivity and volume fraction of water, coal and steam (Table 1). No heat transfers from the center layer $(n=61)$.

\subsection{Heat consumption}

Difference between heat input and output of the $n$-th layer, $\Delta Q_{n}-\Delta Q_{n+1}$, is consumed by rising temperature or 
Table 1 Input parameters for simulation.

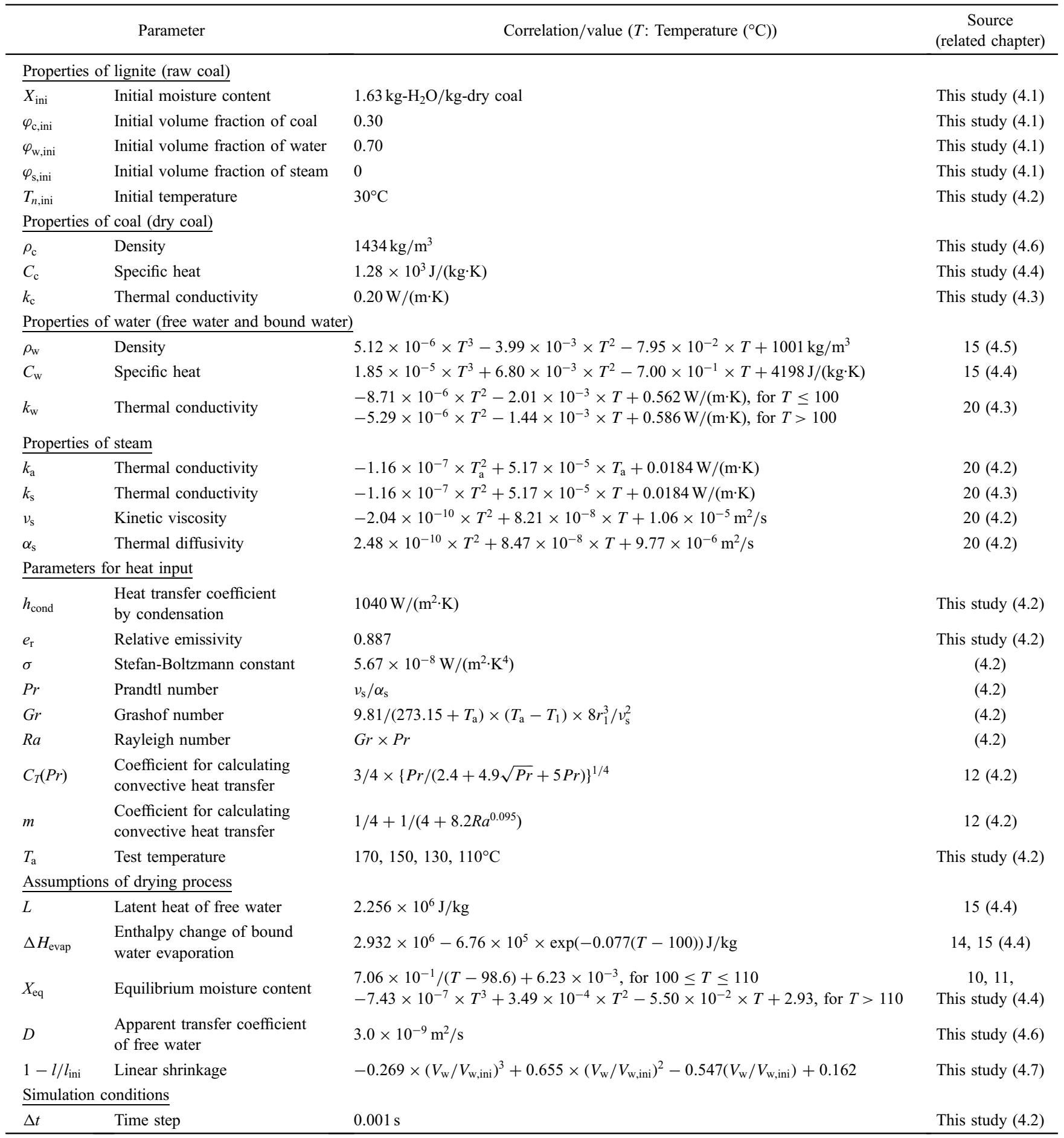

evaporation of water depending on the state. Heat consumption is expressed by eq. (12).

$$
\begin{aligned}
\Delta Q_{n}-\Delta Q_{n+1}= & \left(C_{\mathrm{c}} M_{\mathrm{c}, n}+C_{\mathrm{w}}\left(M_{\mathrm{w}, n}-\Delta M_{\text {evap }, n}\right)\right) \Delta T_{n} \\
& +\Delta M_{\text {evap }, n} \Delta H_{\text {evap }}
\end{aligned}
$$

where $C_{\mathrm{c}}$ and $C_{\mathrm{w}}$ are the specific heat of coal and water, $M_{\mathrm{c}, n}$ and $M_{\mathrm{w}, n}$ the weight of coal and water in the layer. $\Delta T_{n}$ is the temperature increase, $\Delta M_{\text {evap }, n}$ is the weight of water evaporated from the layer and $\Delta H_{\text {evap }}$ is the enthalpy change of evaporation of water. Thermal capacity of steam is neglected.
At an early stage where the temperature of a layer is below $100^{\circ} \mathrm{C}$, heat is consumed only to increase temperature. Because $\Delta M_{\mathrm{evap}, n}$ is zero, eq. (12) is substituted by eq. (13).

$$
\Delta Q_{n}-\Delta Q_{n+1}=\left(C_{\mathrm{c}} M_{\mathrm{c}, n}+C_{\mathrm{w}} M_{\mathrm{w}, n}\right) \Delta T_{n}
$$

After the layer reaches $100^{\circ} \mathrm{C}$, the heat is used only for evaporating free water until it has evaporated completely. Because $\Delta T$ is zero during this period, eq. (12) is substituted by eq. (14) where $L$ is the latent heat of free water at $100^{\circ} \mathrm{C}$.

$$
\Delta Q_{n}-\Delta Q_{n+1}=\Delta M_{\text {evap }, n} L
$$




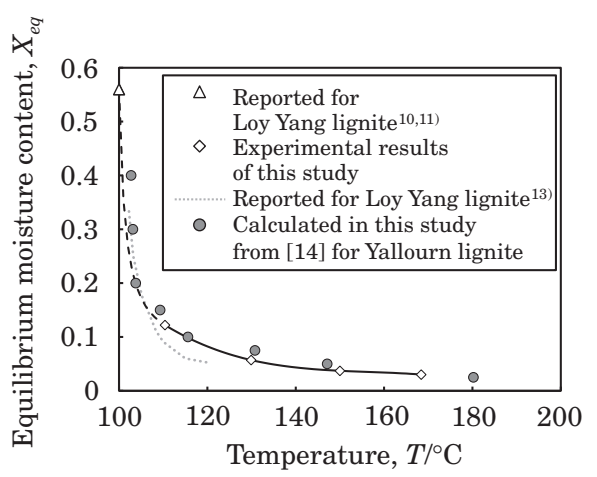

Fig. 12 Equilibrium moisture content curve.

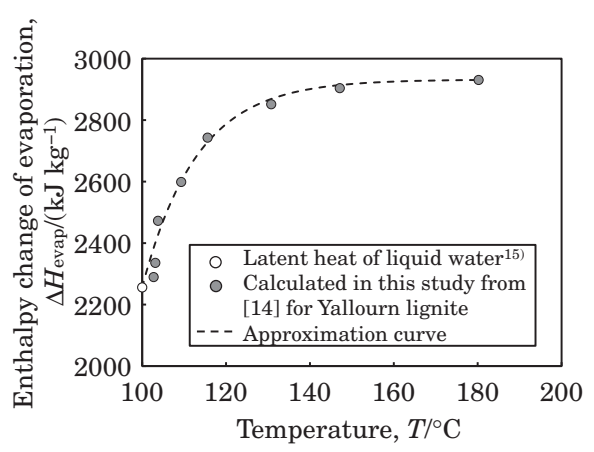

Fig. 13 Relationship between enthalpy change of water vaporization and evaporating temperature under atmospheric pressure.
When the moisture content in the layer, $X_{n}$, becomes 0.56 , free water is regarded to have evaporated completely. Thereafter, the heat is used for both evaporating bound water and increasing temperature.

The Newton method is used to simulate drying during this period, assuming the relationship of $T_{n}$ and $X_{n}$ follows the equilibrium moisture content curve, $X_{\text {eq }}(T)$, shown in Fig. 12. In this figure, moisture content at $100^{\circ} \mathrm{C}$ is based on Loy Yang lignite as described in 4.1. Equilibrium moisture content of Loy Yang lignite below $120^{\circ} \mathrm{C}$ has been reported $^{13)}$ as shown by the dotted line. In this study, the moisture content is assumed to be a linear function of $1 / T$ between 100 and $110^{\circ} \mathrm{C}$. In the range from 110 to $170^{\circ} \mathrm{C}, X_{\text {eq }}$ is obtained from residual water in this study (Fig. 8). Approximate equations are shown in Table 1.

Because bound water evaporates above $100^{\circ} \mathrm{C}, \Delta H_{\text {evap }}$ is assumed to be larger than for free water. The relationship between $\Delta H_{\text {evap }}$ and evaporating temperature is estimated in the following manner. Gibbs energy change for evaporation of bound water is expressed by eq. (15).

$$
\begin{aligned}
\Delta G_{\text {evap }}= & \Delta H_{\mathrm{b}}+\Delta H_{\text {evap }, 1} \\
& -(T+273.15)\left(\Delta S_{\mathrm{b}}+\Delta S_{\text {evap }, 1}\right)
\end{aligned}
$$

where $\Delta H_{\mathrm{b}}$ and $\Delta S_{\mathrm{b}}$ are the enthalpy change and the entropy change for desorption of bound water into free water (liquid), and $\Delta H_{\text {evap }, 1}$ and $\Delta S_{\text {evap }, 1}$ are those for evaporation of free water into steam under atmospheric pressure. $\Delta H_{\mathrm{b}}$ and $\Delta S_{\mathrm{b}}$ for bound water in Yallourn lignite were reported ${ }^{14)}$ to be a function of moisture content. The reported values are assumed to be applicable to Loy Yang lignite and independent of temperature. On the other hand, $\Delta H_{\text {evap, } 1}$ and $\Delta S_{\text {evap,1 }}$ also have been reported. ${ }^{15)}$ Because the bound water evaporates where $\Delta G_{\text {evap }}$ equals zero, evaporating temperature of the water was derived for each moisture content using the reported values above. As Fig. 12 shows, the calculation was consistent with the equilibrium moisture content observed at each test temperature in this study, and thus these assumptions are believed to be valid. Figure 13 shows the relationship between $\Delta H_{\text {evap }}\left(=\Delta H_{\mathrm{b}}+\Delta H_{\text {evap }, 1}\right)$ and evaporating temperature assumed in this model, and its approximate expression is shown in Table 1.

\subsection{Condensation and exudation of water on the surface}

Because the experimental results indicate swelling of water inside the lignite particle during the condensation period, water density is defined as a function of temperature (Table 1). Considering the swollen water forms droplets with condensed steam on the surface, the weight of the water on the surface, $M_{\text {surf }}$, is defined as eqs. (16) and (17).

$$
\begin{array}{r}
\Delta M_{\text {surf }}=\left(\Delta Q_{\text {cond }}-\Delta Q_{\text {conv }}-\Delta Q_{\mathrm{rad}}\right) / L+\Delta M_{\mathrm{ex}}, \\
\text { for } T_{1}<100 \\
\Delta M_{\mathrm{surf}}=\left(\Delta Q_{1}-\Delta Q_{\mathrm{conv}}-\Delta Q_{\mathrm{rad}}\right) / L+\Delta M_{\mathrm{ex}}, \\
\text { for } T_{1}=100
\end{array}
$$

where $\Delta M_{\text {ex }}$ is the weight of the exuded water. $M_{\text {surf }}$ is 0 in the initial state. In the experiments, the falling of the first droplet was observed when sample weight increased $0.16 \mathrm{~g}$ from the initial value (Fig. 6). Based on this observation, the upper limit of $M_{\text {surf }}$ is determined from its value at the point when $0.16 \mathrm{~g}$ of steam condenses on the surface. A water droplet of $0.081 \mathrm{~g}$ is assumed to fall when $M_{\text {surf }}$ exceeds the upper limit. The weight of falling droplets was determined from the average value in all tests (Fig. 6).

\subsection{Transfer of free water}

Free water in lignite is thought to be transferred by capillary pressure gradient, diffusion, or vapor pressure gradient. ${ }^{16,17)}$ Because it is difficult to formulate the transfer, which depends on materials, distributions of pore sizes, pore forms and moisture content, some researchers expressed it for convenience as a function of moisture content using eq. (18). ${ }^{18)}$

$$
\frac{\partial X}{\partial t}=-D \nabla^{2} X
$$

where $D$ is the apparent transfer coefficient. Using this approximation, this model adopts eq. (19).

$$
\begin{aligned}
\Delta M_{\text {trans }, n}= & -D \cdot \rho_{\mathrm{c}} \cdot 4 \pi r_{n+1}^{2}\left(X_{n}-X_{n+1}\right) /\left(d_{n}+d_{n+1}\right) \cdot \Delta t, \\
& \text { for } n \leq 60 \text { and } X_{n+1}>0.56
\end{aligned}
$$

where $\Delta M_{\text {trans }, n}$ is water transfer from $(n+1)$ th layer to $n$-th layer and $\rho_{\mathrm{c}}$ is density of dry coal. The value of $D$ is assumed to be $3 \times 10^{-9}\left(\mathrm{~m}^{2} / \mathrm{s}\right)$, which fits the experimental results.

\subsection{Shrinkage}

In the present model, when water in lignite evaporates, its space is then occupied by steam (Chapter 4.1). To simulate the volume change of lignite during the drying process, the volume of steam is assumed to decrease during drying. Linear shrinkages of rod-shaped samples, $\left(1-l / l_{\text {ini }}\right) \times 100$, are shown in Fig. 9 as a function of moisture content, $X$. 

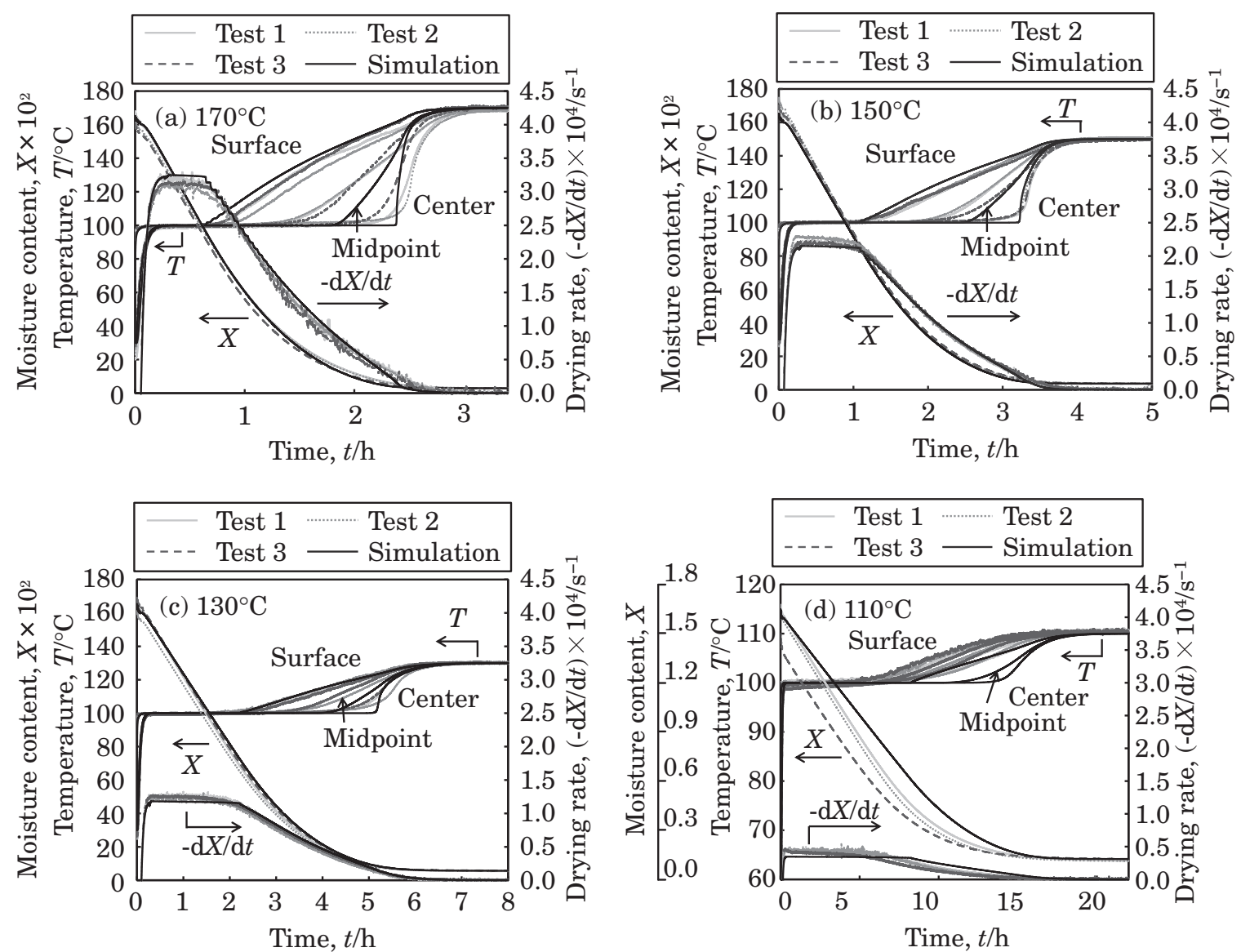

Fig. 14 Simulated moisture contents, drying rates and temperatures compared to experimental results at test temperatures of (a) 170 , (b) 150, (c) 130 and (d) $110^{\circ} \mathrm{C}$.

When modeling drying at higher temperatures, however, $X$ is believed to be unsuitable to express shrinkage because of thermal expansion and the exudation of water. Therefore, the shrinkage in Fig. 9 is converted into a function of water volume, $V_{\mathrm{w}}$, as shown in Table 1 . Initial thickness of each layer is multiplied by linear shrinkage, $1-l / l_{\text {ini }}$, and volume loss is counted as the change in the volume of steam at each layer. Dependence of linear shrinkage on test temperature is corrected by modifying the approximate curve in Fig. 9 according to volume shrinkages measured in experiments (Fig. 8).

\section{Simulation Results and Discussion}

Figure 14 shows simulated moisture contents, drying rates and temperatures. Although moisture contents and drying rates agree well with the experimental results at 130,150 and $170^{\circ} \mathrm{C}$, they show deviations at $110^{\circ} \mathrm{C}$. Based on the disagreement in the drying rate during $\mathrm{CDRP}$, the heat input needs modification. Figure 15 shows simulated results using a corrected convective heat transfer coefficient, $h_{\text {conv }}$, which was modified to be 1.64 times larger than the theoretical value (eq. (6)). Correcting heat input in this manner might be helpful to simulate drying behavior at a temperature near $100^{\circ} \mathrm{C}$.

Simulated surface temperatures agree well with experimental results. However, the temperatures of inner parts (the midpoint and center) started rising from $100^{\circ} \mathrm{C}$ earlier in the

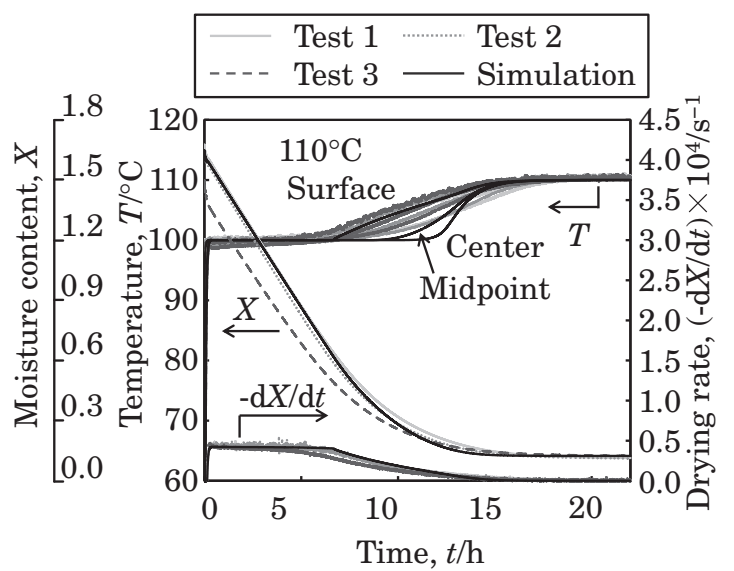

Fig. 15 Simulated results with corrected heat transfer coefficient at $110^{\circ} \mathrm{C}$ compared to experimental results.

experiments than in the simulated results. These deviations are thought to be due to measurement errors caused by conductive heat transfer along thermocouples from outside a sample, as reported in other studies. ${ }^{4,19)}$

Figures 16 and 17 show simulated profiles of moisture content and temperature in a lignite particle, respectively. After drying for $0.5 \mathrm{~h}$ at $170^{\circ} \mathrm{C}$, moisture content is above 0.56 at all positions in the particle, which means free water exists at those locations. Temperatures of the entire particle are maintained at $100^{\circ} \mathrm{C}$ at this time as shown in Fig. 17. 


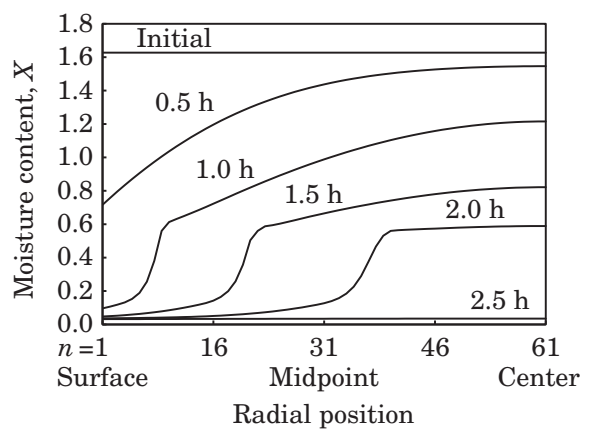

Fig. 16 Simulated profiles of moisture content in a lignite particle $\left(170^{\circ} \mathrm{C}\right)$.

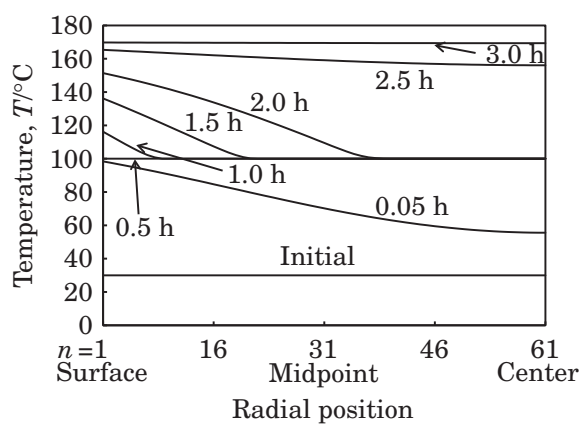

Fig. 17 Simulated profiles of temperature in a lignite particle $\left(170^{\circ} \mathrm{C}\right)$.

CDRP continues in this state. After a lapse of $1.0 \mathrm{~h}$, moisture content at the surface is lower than 0.56 , and surface temperature is above $100^{\circ} \mathrm{C}$. Therefore, free water does not remain, and DDRP has already begun at this time. At 1.0, 1.5 and $2.0 \mathrm{~h}$, the moisture content profiles show steep declines at the boundary of 0.56 . Temperature is above $100^{\circ} \mathrm{C}$ at the outer region where moisture content is below 0.56, and bound water evaporates. Meanwhile, free water evaporates at the frontier where moisture content is above 0.56 , accompanied by a transfer of water from the inner region. Free water is completely evaporated from the particle after $2.5 \mathrm{~h}$, and temperature is above $100^{\circ} \mathrm{C}$ at any position.

Figure 18 shows drying characteristic curves for experimental and simulation results. In the calculation at $110^{\circ} \mathrm{C}$, the corrected heat transfer coefficient is used according to Fig. 15. Simulated drying rates in CDRP are $0.42,1.18,2.15$ and $3.24\left(\times 10^{-4} \mathrm{~kg}-\mathrm{H}_{2} \mathrm{O} /(\mathrm{kg}\right.$-dry coal $\left.\cdot \mathrm{s})\right)$ at $110,130,150$ and $170^{\circ} \mathrm{C}$, respectively. Critical moisture contents, at which CDRP becomes DDRP, are 0.62, 0.74, 0.87 and 1.00, respectively, from simulation results.

\section{Conclusions}

The drying rates of single lignite particles in superheated steam were measured using spherical samples $30 \mathrm{~mm}$ in diameter. The time variations of their weights and temperatures showed both CDRP and DDRP at each test temperature. Temperature dependence of crack generation and volume shrinkage were observed with video images and $3 \mathrm{D}$ scanner. The drying process was completed at 3, 4.5, 7.5 and $21 \mathrm{~h}$ with test temperatures of $170,150,130$ and $110^{\circ} \mathrm{C}$, respectively.

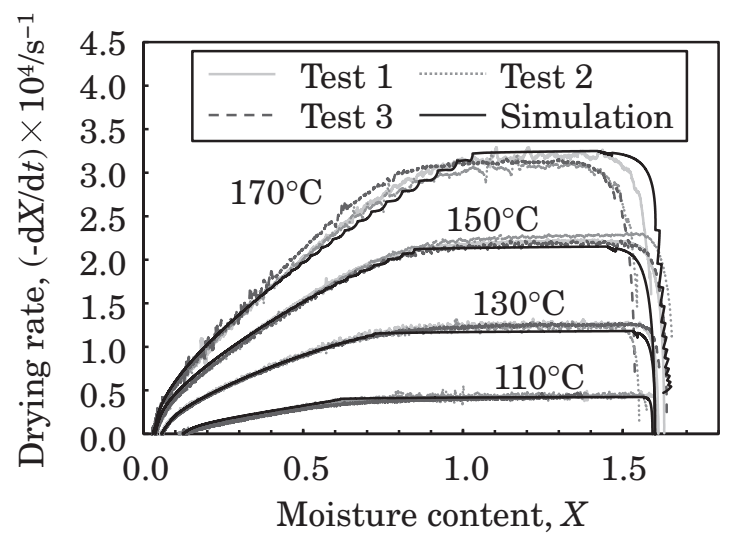

Fig. 18 Drying characteristic curves (experimental and simulation results).

A numerical model of the drying process has been developed taking into account transfer of free water, equilibrium moisture content and shrinkage. The model can predict the drying rate of coarse lignite particles in the temperature range from 110 to $170^{\circ} \mathrm{C}$, and the time required to complete drying.

\section{Acknowledgments}

The authors acknowledge financial support from the Japan Coal Energy Center. Lignite for samples was supplied by Mitsubishi Heavy Industries, LTD.

\section{REFERENCES}

1) A. W. Clarke and J. A. Trinnaman: 2010 Survey of Energy Resources, (World Energy Council, United Kingdom, 2010).

2) S. V. Jangam, M. Karthikeyan and A. S. Mujumdar: Dry. Technol. 29 (2011) 395-407.

3) O. Hoehne, S. Lechner, M. Schreiber and H. J. Krautz: Dry. Technol. 28 (2010) 5-19.

4) K. Zhang and C. You: Energy Fuels 24 (2010) 6428-6436.

5) Z. Chen, W. Wu and P. K. Agarwal: Fuel 79 (2000) 961-974.

6) A. Y. Looi, K. Golonka and M. Rhodes: Chem. Eng. 87 (2002) 329338.

7) Y. Fei, A. Abd Aziz, S. Nasir, W. R. Jackson, M. Marshall, J. Hulston and A. L. Chaffee: Fuel 88 (2009) 1650-1655.

8) R. Toei, M. Okazaki, M. Kimura and K. Kubota: Chem. Eng. Japan 30 (1966) 949-950.

9) D. G. Evans: Fuel 52 (1973) 186-190.

10) D. J. Allardice, L. M. Clemow, G. Favas, W. R. Jackson, M. Marshall and R. Sakurovs: Fuel 82 (2003) 661-667.

11) Y. Fei, A. L. Chafee, M. Marshall and W. R. Jackson: Fuel 84 (2005) 1557-1562.

12) T. Fujii, T. Honda and M. Fujii: Num. Heat Trans. 7 (1984) 103-111.

13) J. Schmalfeld and C. Twigger: VDI BERICHTE 1280 (1996) 107-117.

14) D. J. Allardice and D. G. Evans: Fuel 50 (1971) 201-210.

15) W. Wagner and A. Pruß: J. Phys. Chem. Ref. Data 31 (2002) 387-535.

16) R. B. Bird, W. E. Stewart and E. N. Lightfoot: Transport Phenomena, Second Edition, Other Mechanisms for Mass Transport, (John Wiley \& Sons, 2006) pp. 764-804.

17) L. A. Richards: J. Appl. Phys. 1 (1931) 318-333.

18) W. Gardner and J. A. Widtsoe: Soil Sci. 11 (1921) 215-232.

19) T. Inoue, H. Iyota, N. Nishimura and T. Nomura: Trans. Jpn. Soc. Mech. Eng. B 73 (2007) 1068-1076.

20) JSME Data Book: Thermophysical Properties of Fluids, (The Japan Society of Mechanical Engineers, 1983). 